\title{
PENAMBAHAN FLY ASH DAN SERAT SERABUT KELAPA SEBAGAI BAHAN PEMBUATAN BETON
}

\author{
Eko Siswanto ${ }^{1}$, April Gunarto ${ }^{2}$ \\ ${ }^{1,2}$ Fakultas Teknik Universitas Kadiri \\ email : eko_siswanto@unik-kediri.ac.id, april_gunarto@unik-kediri.ac.id
}

\begin{abstract}
Jobmix variations of concrete are $0 \%, 10 \%, 20 \%, 30 \%$, and $40 \%$. The number of test specimens from each variation was made 3 pieces of specimens in the form of cubes $15 \times 15 \times 15 \mathrm{~cm}$, testing the specimens was carried out at the age of 28 days. By testing compressive strength and absorption.

The results showed that the average compressive strength of concrete in each variation was $0 \%(2800$ $\mathrm{kg} / \mathrm{cm} 2), 10 \%(2520 \mathrm{~kg} / \mathrm{cm} 2), 20 \%(2016 \mathrm{~kg} / \mathrm{cm} 2), 30 \%(1411 \mathrm{~kg} / \mathrm{cm} 2)$ and $40 \%(846 \mathrm{~kg} / \mathrm{cm} 2)$. From the average - compressive strength of concrete in each variation data obtained that the value of compressive strength of concrete with a variation of $10 \%$ is equal to the average value of compressive strength $K-225$. The optimum percentage of coconut fiber fibers in the compressive strength of concrete at a variation of $10 \%$ with the conversion results of $260 \mathrm{~kg} / \mathrm{cm} 3$ reaching $k-225$ quality. Absorption test with addition of coconut fiber fibers and Fly ash in each variation with an average of $1 / 4$ hour $(0.101 \mathrm{ml})$, 1 hour $(0.046 \mathrm{ml}), 4$ hours $(0.016 \mathrm{ml})$, and 24 hours $(0.037 \mathrm{ml})$
\end{abstract}

Keywords: Compressive Strength, Absorption, Coconut Fiber, Fly ash

\begin{abstract}
Abstrak
Variasi beton Jobmix adalah $0 \%, 10 \%, 20 \%, 30 \%$, dan 40\%. Jumlah spesimen uji dari masing-masing variasi dibuat 3 buah spesimen dalam bentuk kubus $15 \times 15 \times 15 \mathrm{~cm}$, pengujian spesimen dilakukan pada umur 28 hari. Dengan menguji kuat tekan dan penyerapan. Hasil penelitian menunjukkan bahwa ratarata kuat tekan beton pada masing-masing variasi adalah $0 \%(2800 \mathrm{~kg} / \mathrm{cm} 2), 10 \%(2520 \mathrm{~kg} / \mathrm{cm} 2)$, $20 \%(2016 \mathrm{~kg} / \mathrm{cm} 2), 30 \%(1411 \mathrm{~kg} / \mathrm{cm} 2)$ dan $40 \%(846 \mathrm{~kg} / \mathrm{cm} 2)$. Dari rata - rata kuat tekan beton pada setiap variasi data diperoleh bahwa nilai kuat tekan beton dengan variasi $10 \%$ sama dengan nilai rata - rata kuat tekan K-225. Persentase optimal serat serabut kelapa dalam kekuatan tekan beton pada variasi $10 \%$ dengan hasil konversi $260 \mathrm{~kg} / \mathrm{cm} 3$ mencapai kualitas $k-225$. Uji absorpsi dengan penambahan serat sabut kelapa dan abu terbang di setiap variasi dengan rata-rata 1/4 jam $(0,101 \mathrm{ml}), 1$ jam $(0,046 \mathrm{ml}), 4$ jam $(0,016 \mathrm{ml})$, dan $24 \mathrm{jam}(0,037 \mathrm{ml})$
\end{abstract}

Kata Kunci: Kekuatan Tekan, Penyerapan, Serat Kelapa, Fly ash

\section{PENDAHULUAN}

\subsection{Tinjauan Umum}

Beton merupakan salah satu komponen penyangga dalam sebuah konstruksi. Beton memiliki fungsi yang vital terutama untuk struktur suatu bangunan. penggunaan beton pada sebuah gedung,ruko,rumah tinggal berbeda dengan penggunaan beton untuk jalan. Pada umumnya beton memiliki tekstur yang padat dan kedap air,hal tersebut juga mempengaruhi berat jenis beton itu sendiri, berat jenis beton normal cenderung tinggi sehingga mempengaruhi 
beban yang di terima oleh pondasi. Selain berat jenis beton yang tinggi bahan baku pembuatan beton pun masih mengandalkan sumber daya alam, salah satunya yaitu penggunaan batu belah atau koral yang biasanya dipakai untuk campuran beton. Hal tersebut apabila terjadi secara terus menerus maka sumber daya alam dapat menipis dan akhirnya habis, maka di perlukan bahan pengganti yang di dapat dari limbah atau bahan yang sudah tidak terpakai lagi. Dalam ilmu teknik sipil inovasi sangat di butuhkan terutama untuk mengatasi permasalahan yang ada,salah satunya masalah dampak lingkungan yang diakibatkan dari penggunaan agregat atau bahan dari alam yang tidak dapat diperbarui dengan cara memanfaatkan limbah dari serabut kelapa fillter sebgai pengganti agregat kasar. Bahan ini dipilih sebagai bahan campuran kerena mengingat di Indonesia sendiri konsumen rokok sangat banyak, dengan adanya pengolahan limbah ini tentu akan mengurangi sampah yang di hasilkan dari para konsumen rokok, selain itu berat jenis dari serabut kelapa sangat ringan sehingga otomatis akan mengurangi berat jenis pada beton.

\subsection{Rumusan Masalah}

Berdasarkan latar belakang masalah diatas maka dapat dikemukakan beberapa masalah sebagai berikut :

Pengaruh penggunaan limbah serabut kelapa filter sebagai pengganti agregat kasar pada beton berpori terhadapkuat tekan, berat jenis beton, nilai angka pori , nilai porositas pada beton K-125.

\section{METODE PENELITIAN}

\subsection{Material}

Material yang digunakan untuk pembuatan beton ini berupa Semen Portland merk Semen Gresik jenis (PC), Agregat halus (Pasir Gunung Kelud Kediri), Agregat kasar dari Limbah Serabut kelapa Fillter yang ada di kediri,dan Air yang diambil dari PDAM Universitas Kadiri

\subsubsection{Serat Serabut Kelapa}

Serat serabut kelapa adalah salah satu biomassa yang mudah di dapatkan pada hasil samping pertanian. Buah kelapa memiliki komposisi sabut sebesar 35\% dari berat keseluruhan buah kelapa. Sabut kelapa terdiri dari serat ( Fiber) dan gabus ( Pitch ) yang menghubungkan satu serat dengan serat yang lainnya. Sabut kelapa terdiri dari $75 \%$ serat dan $25 \%$ gabus. 


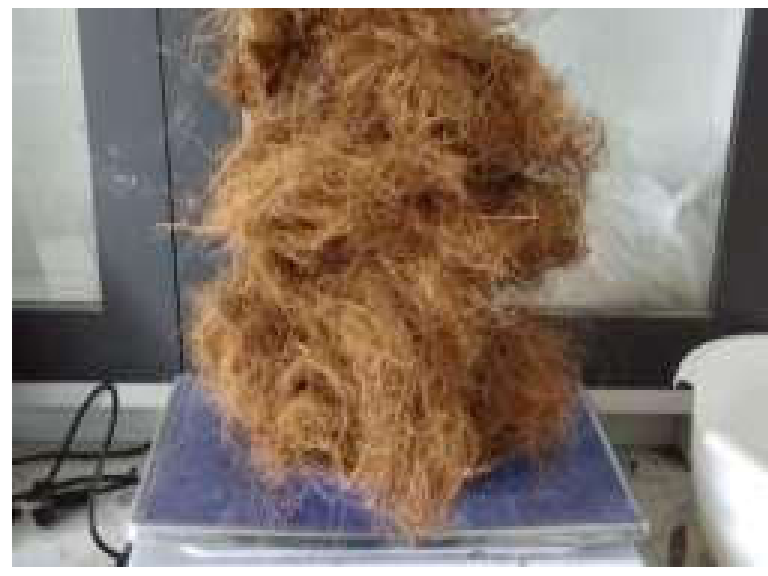

Gambar 1: Serabut Kelapa

\subsubsection{Semen Portland (PC)}

Semen adalah suatu bahan yang memiliki sifat adhesif dan kohesif yang memungkinkan melekatnya fragmen mineral menjadi suatu benda padat. Semen merupakan bahan yang dapat mengeras jika bereaksi dengan air, hal ini adalah yang dinamakan semen hidraulis. Semen portland atau biasa di sebut semen adalah bahan pengikat hidroli berupa bubuk halus yang dihasilkan dengan cara menghaluskan klinker, dengan batu gips sebagai bahan tambahan. Semen yang digunakan adalah semen portland tipe I.

\subsubsection{Air}

Air adalah bahan dasar pembuatan beton. Fungsi air dalam pembuatan beton untuk membuat semen bereaksi dan sebagai bahan pelumas antara agregat kasar dan halus. Untuk membuat semen bereaksi hanya dibutuhkan air sekitar 25\%-30\% dari berat semen tersebut. Tetapi pada kenyataan dilapangan apabila faktor air semen. Kelebihan air inilah yang berfungsi sebagai pelumas agregat, sehingga membuat adukan mudah dikerjakan. Tetapi seiring dengan semakin mudahnya pengerjaan, maka akan menyebabkan beton menjadi porus, maka kuat tekan beton juga akan menurun.

\subsubsection{Agregat Halus}

Agregat halus untuk beton dapat berupa pasir alam sebagai hasil disintegrasi alami dari batubatuan atau berupa pasir buatan yang dihasilkan oleh alat-alat pemecah batu. Agregat halus pada penelitian ini menggunakan jenis agregat halus yaitu pasir alami, pasir ini merupakan pasir alami yang diambil dari lereng gunung kelud. pasir yang diambil dari kelud termasuk ke dalam jenis pasir galian karena dalam pengambilannya dengan cara digali. Ditinjau dari asalnya, pasir yang dipakai dalam pengujian ini adalah pasir yang berasal dari erupsi gunung kelud. Sehingga dapat disimpulkan bahwa pasir yang digunakan adalah pasir kelud yang termasuk jenis pasir kasar.

\subsection{Pengujian Kuat Tekan Beton}


Nilai kuat tekan beton didapatkan melalui tata cara pengujian standar, menggunakan mesin uji dengan cara memberikan beban tekan bertingkat pada benda uji silinder beton (diameter 150 $\mathrm{mm}$, tinggi $300 \mathrm{~mm}$ ) sampai hancur. Untuk standar pengujian kuat tekan digunakan SNI 036805 - 2002 dan ASTM C 39/C 39M-04a.

$\mathrm{K}=\quad \mathrm{P} / \mathrm{A}$

Dimana

$\mathrm{K}=$ Kuat tekan beton $\left(\mathrm{kg} / \mathrm{cm}^{2}\right)$

$\mathrm{P}=$ Gaya tekan aksial, dinyatakan dalam newton $(\mathrm{N})$

$\mathrm{A}=$ Luas penampang melintang benda uji, dinyatakan dalam $\mathrm{cm}^{2}$

Sumber :(SNI 03-1974-1990, 1990)(Hunggurami, 2017)

\subsection{Pengujian Nilai Absorsi}

Pengujian daya serap beton adalah kemampuan bahan dalam menyerap air. Bobot isi adalah perbandingan massa dalam keadaan kering dengan bobot dalam kondisi jenuh air. Daya serap air tinggi akan berpengaruh pada pamasangan paving beton berpori dan adukan karena air pada aduka di resap oleh agregat serabut kelapa. Sehingga daya resap yang tinggi disebabkan oleh besarnya kadar pori. Untuk mengatahui seberapa cepat beton tersebut dapat menyerap air maka dilakukan pengujian ketika beton dalam keadaan kering lalu direndam dengan melihat penyerapan air pada waktu periode tertentu seperti pada waktu 1/4 jam, 1 jam, 4 jam dan 24 jam. Besarnya absorpsi pada paving block sesuai ASTM adalah :

\section{At $=($ Wt-W0) $x 10000 / L 1 \times L 2$}

$\mathrm{Wt}=$ berat benda uji pada waktu $\mathrm{T}$ (gram).

W0 $=$ berat tetap awal benda uji (gram).

Sumber : SNI $1970: 2008$

\subsection{Pengujian Berat Jenis Beton}

Pengujian berat jenis beton dengan cara menimbang berat solid lalu membaginya dengan volume beton maka terbentuk nilai berat jenis beton. Sehigga di rumuskan sebagai berikut :

berat jenis $(\gamma)=\underline{\mathrm{W}}$

$\mathrm{V}$

Dimana :

$\mathrm{W}=$ Berat Total $(\mathrm{Kg})$

$\mathrm{V}=$ Volume Total $\left(\mathrm{m}^{3}\right)$

\section{HASIL DAN PEMBAHASAN}

\subsection{Hasil Pemeriksaan Uji Agregat}


Material dan bahan yang digunakan dalam penelitian ini meliputi Semen portland, air, limbah serabut kelapa fillter yang berfungsi sebagai pengganti agregat kasar, pasir. Sebelum digunakan untuk membuat benda uji, material dan bahan dtersebut harus terlebih dahulu dilakukan pemeriksaan karakteristiknya. Pemeriksaan ini dilakukan di Laboratorium Teknik Sipil Universitas Kadiri. Hasil rekapitulasi peeriksaan awal agregat disajikan dalam tabel seperti di bawah ini.

Tabel 1: Rekapitulasi Pemeriksaan Karakteristik Agregat Halus

\begin{tabular}{|c|l|c|c|c|}
\hline NO & Karakteristik Agregat & interval Spesifikasi & Hasil uji & keterangan \\
\hline 1 & kadar air & $2 \%-5 \%$ & $2,79 \%$ & Memenuhi \\
\hline 2 & Berat Volume & $1,6-1,9 \mathrm{~kg} /$ liter & $1,61 \mathrm{Kg} / \mathrm{Liter}$ & Memenuhi \\
\hline 3 & Absorsi & Maks $2 \%$ & $0,81 \%$ & Memenuhi \\
\hline & Berat Jenis & & & \\
\hline & a. Bj. Curah & $1,6-3,3$ & 2,48 & Memenuhi \\
\hline & b. Bj. Kering Permukaan & $1,6-3,3$ & 2,5 & Memenuhi \\
\hline & c. Bj. Semu & $1,6-3,3$ & 2,53 & Memenuhi \\
\hline 4 & Modulus Kehalusan & $1,5-3,8$ & 2 & Memenuhi \\
\hline 5 & Kadar Lumpur & Maks $5 \%$ & $2,40 \%$ & Memenuhi \\
\hline
\end{tabular}

\subsection{Hasil Perhitungan Rencana Campuran (JobMix Design)}

Dalam penelitian ini, perhitungan komposisi campuran yang digunakan dalam pembuatan benda uji mengacu pada SNI 7394 : 2008 tentang adukan beton setiap $1 \mathrm{~m}^{3}$. Mutu Beton yang digunakan yaitu K-250 dengan target hasil adalah K-100. Dengan 5 buah benda uji untuk beton modifikasi dengan serabut kelapa. Dengan perbandingan antara berat jenis limbah serabut kelapa fillter dengan berat jenis batu belah di rumuskan komposisi material seperti bentuk tabel seperti di bawah ini

Tabel 2: Komposisi Material Beton Limbah Serabut kelapa Untuk Kebutuhan tiap $1 \mathrm{~m}^{2}$ 


\begin{tabular}{|c|l|c|c|c|c|}
\hline NO & \multicolumn{1}{|c|}{$\begin{array}{c}\text { Material Mix } \\
\text { K-125 } \\
\text { SNI 7394-2008 }\end{array}$} & Berat & Sat. & Presentase & Sat. \\
\hline 1 & Semen & 2 & $\mathrm{~K}$ & 26,6 & $\%$ \\
\hline 2 & Air & 2 & $\mathrm{~K}$ & 14,9 & $\%$ \\
\hline 3 & Serabut Kelapa & 148, & $\mathrm{~K}$ & 10,32 & $\%$ \\
\hline 4 & Pasir Total & 8 & $\mathrm{~K}$ & 48,0 & $\%$ \\
\hline \multicolumn{2}{|r|}{} & 1439, & $\mathrm{~K}$ & 10 & $\%$ \\
\hline
\end{tabular}

Sumber : Data diolah

\subsection{Hasil Pengujian Kuat Tekan Benda Uji}

Pengujian kuat tekan pada benda uji beton menggunakan alat kuat tekan hidrolis dengan kuat tekan mencapai 500 ton. Benda uji yang dipakai berdimensi 15 x 15 x $15 \mathrm{~cm}$ dengan umur 28 hari. Tes kuat tekan ini berdasarkan SNI 03-1974-1996.

Data yang di hasilkan dari alat test kuat tekan maka akan diolah seperti contoh di bawah ini :

$\mathrm{K}=\mathrm{P} / \mathrm{A}$
$\mathrm{K}=$
$26000 \mathrm{~kg}$
$225 \mathrm{~cm}^{2}$
$115,56 \mathrm{Kg} / \mathrm{cm}^{3}$

Tabel 3: Tabel Test Kuat Tekan Beton Modifikasi Limbah Serabut kelapa

\begin{tabular}{|c|c|c|c|c|c|}
\hline NO & Benda Uji & $\begin{array}{c}\text { Angka Dial } \\
\text { Newton }\end{array}$ & $\begin{array}{c}\text { Angka Dial di } \\
\text { Jadikan Kg }\end{array}$ & $\begin{array}{c}\text { Luas penampang 15 x } \\
15 \mathrm{~cm}(\mathrm{~A})\end{array}$ & $\begin{array}{c}\text { Hasil test ( K ) } \\
\text { Kuat Tekan } \\
\left(\mathrm{Kg} / \mathrm{cm}^{2}\right)\end{array}$ \\
\hline 1 & Sampel 1 & 26 & 26000 & 225 & 115,56 \\
\hline 2 & Sampel 2 & 19 & 19000 & 225 & 84,44 \\
\hline 3 & Sampel 3 & 24 & 24000 & 225 & 106,67 \\
\hline 4 & Sampel 4 & 24,5 & 24500 & 225 & 108,89 \\
\hline 5 & Sampel 5 & 19,5 & 19500 & 225 & 86,67 \\
\hline \multicolumn{7}{|c|}{ rata-rata } & 100,44 \\
\hline
\end{tabular}

Sumber : Data diolah

\subsection{Hasil Pengujian Absorsi}

Pengujian absorsi dilakukan ketika beton berumur 25 hari dan di angkat dari proses curing lalu di diamkan 24 jam hingga beton kering, baru kita lakukan tes absorsi dengan pengambilan data ketika beton di rendam selama $1 / 4$ jam, 1 jam,4 jam hingga 24 jam, data yang di hasilkan sebagai berikut.

At $=($ Wt-W0) $\times 10000 /($ L1 x L2)

$A t=(4,900-4,790) \times /(15 \times 15)$

$\mathrm{Wt}=$ berat benda uji pada waktu $\mathrm{T}(\mathrm{Kg})$.

$\mathrm{W} 0=$ berat tetap awal benda uji $(\mathrm{Kg})$. 
L1 $\mathrm{x} \mathrm{L} 2$ = luas penampang beton $\left(\mathrm{cm}^{2}\right)$

Tabel 4: Tabel Test Absorsi Beton Limbah Serabut kelapa

\begin{tabular}{|c|c|c|c|c|c|c|c|c|c|c|}
\hline \multirow[b]{2}{*}{ Variasi } & \multirow[b]{2}{*}{ Sampel } & \multirow{2}{*}{$\begin{array}{c}\text { Berat } \\
\text { Kering } \\
(\mathrm{Kg})\end{array}$} & \multicolumn{4}{|c|}{ Berat Kadar Air } & \multicolumn{4}{|c|}{ Absropsi (kg) } \\
\hline & & & $\begin{array}{l}\mathrm{I} / 4 \\
\mathrm{Jam}\end{array}$ & $\mathrm{I}$ & $\begin{array}{c}4 \\
\mathrm{Jam}\end{array}$ & $\begin{array}{c}24 \\
\mathrm{Jam}\end{array}$ & $\begin{array}{l}/ 4 \\
\mathrm{jam}\end{array}$ & $\underset{\text { jam }}{1}$ & $\begin{array}{c}4 \\
\text { jam }\end{array}$ & $\begin{array}{c}24 \\
\text { jam }\end{array}$ \\
\hline \multirow[t]{3}{*}{ BTN } & 1 & 7.840 & 7.860 & 7.890 & 7.895 & 7.900 & 0.020 & 0.030 & 0.005 & 0000 \\
\hline & 2 & 7.775 & 7.780 & 7.795 & 7.810 & 7.825 & 0.005 & 0.015 & 0.015 & 0.015 \\
\hline & 3 & 7.675 & 7.680 & 7.695 & 7.700 & 7.720 & 0.005 & 0.015 & 0.005 & 0.020 \\
\hline \multirow[t]{3}{*}{ BT 10} & 1 & 7.225 & 7.250 & 7.310 & 7.325 & 7.350 & 0.025 & 0.060 & 0.015 & 0.02 \\
\hline & 2 & 7.810 & 7.825 & 7.840 & 7.845 & 7.860 & 0.015 & 0.015 & 0.005 & 0.015 \\
\hline & 3 & 7.500 & 7.510 & 7.525 & 7.550 & 7.560 & 0.010 & 0.015 & 0.025 & 0.010 \\
\hline \multirow[t]{3}{*}{ BT 20 } & 1 & 7.640 & 7.650 & 7.655 & 7.670 & 7.695 & 0.010 & 0.005 & 0.015 & 0.025 \\
\hline & 2 & 7.080 & 7.100 & 7.150 & 7.225 & 7.250 & 0.020 & 0.050 & 0.075 & 0.025 \\
\hline & 3 & 7.475 & 7.480 & 7.500 & 7.525 & 7.550 & 0.005 & 0.020 & 0.025 & 0.025 \\
\hline \multirow[t]{3}{*}{ BT 30} & 1 & 6.800 & 6.815 & 6.830 & 6.850 & 6.870 & 0.015 & 0.015 & 0.020 & 0.020 \\
\hline & 2 & 6.580 & 6.600 & 6.620 & 6.675 & 6.680 & 0.020 & 0.020 & 0.055 & 0.005 \\
\hline & 3 & 6.835 & 6.850 & 6.875 & 6.900 & 6.910 & 0.015 & 0.025 & 0.025 & 0.010 \\
\hline \multirow[t]{3}{*}{ BT 40 } & 1 & 7.140 & 7.160 & 7.180 & 7.200 & 7.240 & 0.020 & 0.020 & 0.020 & 0.040 \\
\hline & 2 & 6.950 & 7.1 & 7.125 & 7.225 & 7.305 & 0.150 & 0.025 & 0.100 & 0.080 \\
\hline & 3 & 6.990 & 7.110 & 7.150 & 7.220 & 7.250 & 0.120 & 0.040 & 0.070 & 0.030 \\
\hline
\end{tabular}

Sumber : Data diolah

\subsection{Hasil Pengujian Angka Pori}

Pengujian angka pori yaitu angka yang menunjukkan perbandingan antara volume rongga dan volume butiran, hasil dari pengujian ini akan disajikan sebagai berikut.

$$
\operatorname{angka} \operatorname{pori}(\mathrm{e})=\frac{\mathrm{Vv}}{\mathrm{Vs}_{\mathrm{s}}}
$$

Tabel 5: Tabel hasil perhitungan angka pori beton modifikasi limbah serabut kelapa. 


\begin{tabular}{|c|c|c|c|c|c|c|}
\hline No & Variasi & Kode & $\begin{array}{l}\text { Vol Void } \\
\text { (Vv) } \mathrm{cm} 3\end{array}$ & $\begin{array}{l}\text { Vol Solid } \\
\text { (Vs } \\
\text { ) } \mathrm{cm} 3\end{array}$ & $\begin{array}{l}\text { Angka } \\
\text { Pori } \\
\text { (e ) } \mathrm{cm} 3\end{array}$ & $\begin{array}{c}\text { Rata - } \\
\text { rata }\end{array}$ \\
\hline 1 & BTN & 1 & 67.50 & 3307.50 & 0.02 & \multirow{3}{*}{0.043} \\
\hline & & 2 & 174.92 & 3200.08 & 0.05 & \\
\hline & & 3 & 177.08 & 3197.92 & 0.06 & \\
\hline \multirow[t]{3}{*}{2} & BT 10 & 1 & 123.75 & 3251.25 & 0.04 & \multirow{3}{*}{0.038} \\
\hline & & 2 & 120.83 & 3254.17 & 0.04 & \\
\hline & & 3 & 129.81 & 3245.19 & 0.04 & \\
\hline \multirow[t]{6}{*}{3} & BT 20 & 1 & 151.88 & 3223.13 & 0.05 & \multirow{3}{*}{0.055} \\
\hline & & 2 & 230.92 & 3144.08 & 0.07 & \\
\hline & & 3 & 140.63 & 3234.38 & 0.04 & \\
\hline & BT30 & 1 & 209.48 & 3165.52 & 0.07 & \multirow{3}{*}{0.071} \\
\hline & & 2 & 247.18 & 3127.82 & 0.08 & \\
\hline & & 3 & 214.98 & 3160.02 & 0.07 & \\
\hline \multirow[t]{3}{*}{5} & BT 40 & 1 & 73.97 & 3301.03 & 0.02 & \multirow{3}{*}{0.068} \\
\hline & & 2 & 288.65 & 3086.35 & 0.09 & \\
\hline & & 3 & 270.89 & 3104.11 & 0.09 & \\
\hline
\end{tabular}

Sumber : Data diolah

\subsection{Hasil Pengujian Nilai Porositas}

Nilai porositas beton adalah kemampuan beton dalam menyerap air berkaitan dengan tingkat kepadatannya, Hasil pengujian porositas pada benda uji beton modifikasi dan beton normal disajikan dalam bentuk tabel sebagai berikut : Rumus untuk mencari nilai porositas :

$$
\text { porositas }(n)=\frac{E}{1+e}
$$

Tabel 6: Tabel hasil perhitungan porositas beton modifikasi dari limbah serabut kelapa.

\begin{tabular}{|c|c|c|c|c|}
\hline Wo & Tariasi & Koda & Porositas (n) & Rata - Rata \\
\hline 1 & $B T^{N}$ & 1 & 0.02 & \multirow{3}{*}{0.041} \\
\hline & & 2 & 0.05 & \\
\hline & & 3 & 0.05 & \\
\hline \multirow[t]{3}{*}{2} & BI 10 & 1 & [1].10 4 & \multirow{3}{*}{0.037} \\
\hline & & 2 & 10.04 & \\
\hline & & 3 & 10.04 & \\
\hline \multirow[t]{3}{*}{3} & BI 20 & 1 & 0.105 & \multirow{3}{*}{0.052} \\
\hline & & 2 & 10.107 & \\
\hline & & 3 & 10.104 & \\
\hline \multirow[t]{3}{*}{4} & BT 30 & 1 & 9.106 & \multirow{3}{*}{0.066} \\
\hline & & 2 & 0.07 & \\
\hline & & 3 & 0.06 & \\
\hline \multirow[t]{3}{*}{5} & $\mathrm{BT} 40$ & 1 & 0.02 & \multirow{3}{*}{0.063} \\
\hline & & 2 & 0.09 & \\
\hline & & 3 & 10.08 & \\
\hline
\end{tabular}

Sumber : Data diolah 


\section{KESIMPULAN}

Dari hasil analisis dan pembahasan dapat ditarik beberapa kesimpulan yaitu :

1) Rata - rata tiap variasi beton dapat disimpulkan bahwa hasil kuat tekan beton denga penambahan serat serabut kelapa dan fly ash mampu mencapai target K-225 pada variasi BT $10 \%$ dengan sebesar $252 \mathrm{~kg} / \mathrm{cm}^{2}$ hasil kuat tekan

2) Serat serabut beton $10 \%$ kelapa yang optimal untuk campuran beton pada variasi

3) Hasil Uji Absropsi rata - rata tertinggi pada variasi BT 40\%

4) Hasil Uji Angka Pori rata - rata tertinggi pada variasi $0.071 \mathrm{~cm}^{3} \mathrm{BT} 30 \%$ sebesar

5) Hasil Uji Porositas rata - rata tertinggi pada variasi BT 30\% sebesar 0.066

6) Hasil Uji Derajat Kejenuhan rata - rata pada variasi BT $10 \%$ sebesar $0.0023 \mathrm{~cm}^{3}$

7) Hasil Uji Kadar Air rata - rata pada variasi BT 30\% sebe ar $0.07 \%$

8) Hasil Uji Berat Jenis rata - rata pada variasi BT $10 \%$ sebesar $0.0023 \mathrm{~kg} / \mathrm{cm}^{3}$

\section{DAFTAR PUSTAKA}

[1] A D Limantara, A Widodo, S Winarto, L. D. K. and S. W. M. (2017). „Optimizing The Use Of Natural Gravel Brantas River As Normal Concrete Mixed With Quality $\mathrm{Fc}=19$. $3 \mathrm{Mpa}^{\mathrm{ee}}$, IOP Conference Series, (Earth and Environmental Science PAPER). doi: 10.1088/1755-1315/140/1/012104.

[2] Bilqis, Sheba. 2012. Studi Kuat Tekan Pada Mortar Yang Mengandung Rice Husk Ash (Rha) Dan Concrete Sludge Waste (Csw) Dengan Komposisi Semen, Agregat Halus 1:3. Depok: Departemen Teknik Sipil, Universitas Indonesia.

[3] Defoirdt N, Biswas S, De Vriese L, Ngoc Tran LQ, Van Acker J, Ahsan W, Gorbatikh L, Van Vuure A, Verpoest I. 2010. “Assessment Of The Tensile Properties Of Coir, Bamboo And Jute Fibre". Compos A 41:588-595

[4] Dimitrioglou, N, P E Tsakiridis, N S Katsiotis, M S Katsiotis, P Perdikis, and M Beazi. 2015. "Production and Characterization of Concrete Paving Blocks Containing Ferronickel Slag as a Substitute for Aggregates.” Waste and Biomass Valorization. Springer Netherlands. https://doi.org/10.1007/s12649-015-9465-1.

[5] Barros, Joaquim A O, Liberato Ferrara, and Enzo Martinelli. 2017. Recent Advances on Green Concrete for Structural Purposes. Edited by Enzo 
Martinelli. Milan: Springer International Publishing.

https://doi.org/10.1007/978-3-319-56797-6.

[6] Frias M, Savastano H, Villar E, Sanchez de Rojas MI, Santos S. 2012.

"Characterization And Properties Of Blended Cement Matrices Containing

Activated Bamboo Leaf Wastes". Constr Build Mater 34:1019-1023

[7] Ghavami K. 1995. "Ultimate Load Behaviour Of Bamboo-Reinforced

Lightweight Concrete Beams". Cem Concr Compos 17:281-28

[8] SNI 1970:2008.Medote PengujianBeratJenis Dan Penyerapan Agregat Halus.

Departemen Pekerjaan Umum. Jakarta.

[9] SNI 03-2847-2002.Tata Cara Perhitungan Struktur Beton Untuk Bangunan Gedung. Bandung.

[10] SNI 02-6820-2002.Spesifikasi AgregatHalusUntukPekerjaanAdukan Dan

PlesteranDenganBahanDasarSemen.BadanStandarisasiNasional.Jakarta.

[11] SNI 03-1971-1990.1990. Metode Pengujian Kadar Air Agregat. Badan Standarisasi Nasional. Jakarta.

[12] SNI 15-2049-2004. 2004. Semen Portland. Badan StandarisasiNasional. Jakarta.

[13] Tjokrodimulyo, K. 1995.Teknologi Beton.JurusanTeknikSipilUGM.Yogyakarta.

[14] Rusyandi, K., Mukodas, J., \& Gunawan, Y. (2012). Perancangan Beton Self Compacting Concrete (Beton Memadat Sendiri) Dengan Penambahan Fly Ash dan Structuro. Jurnal Konstruksi, 10(01).

[15] Zahraee, S. M., Hatami, M., Yusof, N. M., Rohani, J. M., \& Ziaei, F. (2013). Combined use of design of experiment and computer simulation for resources level determination in concrete pouring process. Jurnal Teknologi, 64(1). 